\title{
Vector Velocity Imaging can be used to analyze function and dyssynchrony of the right ventricle in patients with tetralogy of
} Fallot

\author{
Jiade $\mathrm{Yu}^{*}$, Michael Salerno and Andrew W Hoyer
}

Address: University of Virginia, Charlottesville, VA, USA

* Corresponding author

from 13th Annual SCMR Scientific Sessions

Phoenix, AZ, USA. 21-24 January 2010

Published: 21 January 2010

Journal of Cardiovascular Magnetic Resonance 20 I0, I2(SuppI I):P28 doi: I0.I I86/I532-429X-I2-SI-P28

This abstract is available from: http://jcmr-online.com/content/I2/SI/P28

(c) 2010 Yu et al; licensee BioMed Central Ltd.

\section{Introduction}

Vectory Velocity Imaging was developed to evaluate myocardial dynamics of echocardiographic data, and has been used to analyze echocardiograms of the left ventricle in patients with tetralogy of Fallot. We have harnessed the software to analyze CMR images of the right ventricle in patients with tetralogy of Fallot

\section{Purpose}

To use Vector Velocity Imaging software to analyze right ventricular mechanics in patients with tetralogy of Fallot as seen in CMR cine

\section{Methods}

Siemens Vector Velocity Imaging software was enabled to analzye CMR cine data. Peak systolic strain, systolic and diastolic strain rate, and systolic dyssynchrony (mean time to peak systolic strain and strain rate) were compared for the right ventricle in the four chamber view by CMR cine of 10 patients with tetralogy of Fallot (mean age 10 years, 5 males) and 10 normal patients (mean age 19 years, 3 males)

\section{Results}

Peak systolic strain and peak systolic and diastolic strain rate are lower and dyssynchrony is significantly higher, in the right ventricle in patients with tetralogy of Fallot compared to normal patients

\section{Conclusion}

Vector Velocity Imaging of CMR cine data can be used in patients with tetralogy of Fallot to analyze function and dyssynchrony of the right ventricle 